\title{
PEDAGOGICAL PRACTICE AS A KEY TO REAL PEDAGOGUE'S SUCCESS SOLUTION
}

\author{
Vincentas Lamanauskas \\ University of Šiauliai, Lithuania \\ E-mail: v.lamanauskas@ef.su.It
}

Pedagogical practice preparing future teachers is, undoubtedly, one of the most important elements of university studies. However, up to now pedagogical practice remains a very problematic sphere. Pedagogical activity, on the whole, is complicated, diverse and manifold. After all, it is an activity requiring creativity, high intellect and good psychological preparation. A student doing pedagogical practice, inevitably encounters various hardships -both specialty/professional and psychological. During the practice many different kinds of pedagogical situations are revealed. Various scientific research studies, carried out in the last few years, show the common situation - students-practitioners lack psychological preparation in communication with students, adjusting to a new environment, understanding them and so on. Actually, pedagogical practice theoretical and practical questions were discussed in the international scientific conference which took place between 1- 5 July, 2013 in Yerevan (Armenia). The conference under the theme „Modernization of Continuous Practice and Implementation of Organizational Mechanisms in the Higher Pedagogical Education System" was organised by Armenian State Pedagogical University named after Khachatur Abovyan.

Pedagogical practice organization questions, innovative practice approaches were discussed in the conference. Very often universities do not attach enough attention to this sphere, doing the practice in itself is rather formal. One of the essential questions is the type of practice. During the conference a position was expressed, that pedagogical practice has to be constant and continuous. In other words, it has to cover all the period of bachelor studies. From the very first course the student has to adequately be acquainted with the real school activity, with the real educational process and according to possibilities take part in it. This can be observation of educational process, analysis, discussion, experience accumulation and so on. It can be thought, that pedagogical practice is usually performed in senior courses. Its amount measuring in study credits is not big. Nowadays, the universities are looking for possibilities to involve students into pedagogical practice already from the first course. The other important aspect is - the process of spread, development and maturity of student's acquired competencies takes place during pedagogical practice. Effective feedback should guarantee study process changes. In this respect, clearly fixed pedagogical practice content is a significant thing. Quite often this cannot be achieved, because students, doing pedagogical practice, get a lot of tasks according to studied university subjects. Not always their activity and responsibility limits are notified clearly during practices. Very often the dichotomy between educational (didactic) and psychological tasks can be observed. It is understandable, that carrying out various psychological tasks (e.g., related to students' personality cognition, their individual trait observation, interrelationship diagnostics and so on) students are not able to integrate their results into the educational process. In other words, pedagogical practice is a perfect period in the whole study process to relate the acquired pedagogical (didactic) and psychological knowledge into entire wholeness and be able to apply it practically. Pedagogical practice shows at the same time whether a young man wants and is capable to work at school. Capability is understood here as psychological preparation, susceptibility for development. On the other hand, university studies are quite often criticized because of too strong theorization. Students learn quite a lot; get acquainted with the newest educational, psychological theories. However, real application of acquired knowledge and abilities 
is quite another sphere. Pedagogical psychology can be thought to be that bridge which integrates pedagogical theory and practice.

One more significant thing is that during practices students usually refer to personal examples that they possess. First of all, student practitioner does not apply what he was taught and he learnt, but copies what he saw during his school and study years. In this respect, it is very important what sort of teachers' team takes part preparing future teacher.

Mentor's role in the pedagogical practice process was also a point of discussion during the conference. Pedagogical practice has to undoubtedly be carried out with the support of a mentor. Student practitioner not only does various educology, psychology, health education practical tasks or gives fragments of a subject lesson or conducts educational events. He has to learn observe, analyse, evaluate, reflect on the other pedagogues and students' conducted lessons and events and another performed professional activity. Mentor, here carries out the role of coordinator, advises and consults the practitioner. Mentor preparation for the pedagogical practice leadership becomes very urgent. Apart from the mentor, the school where students do the practice is of great importance too. Experience shows that quite often students do the practice in such institutions which often are not prepared for such an activity. Simply speaking, students should do the practice in the best schools where they could check themselves and take over the newest experience. This aspect also requires deeper thoughts.

Thus, the problematics of pedagogical practice remains topical. How to achieve, that it were an effective instrument not only helping the student to develop, but also to understand the essence of pedagogical activity, to realise your calling and possibilities to do a very complicated and responsible pedagogue's job in future. Can we agree with the statement, that there has to be left as little theory as possible, and to transform all theory into practice? It is obvious, that pedagogical practice process, should considerably be improved, adapted to the time period. How to do this? The question remains open. 